(C) 2018, The Authors. Published by FASS Inc. and Elsevier Inc. on behalf of the American Dairy Science Association ${ }^{\circledR}$. This is an open access article under the CC BY-NC-ND license (http://creativecommons.org/licenses/by-nc-nd/4.0/).

\title{
Is rumination time an indicator of methane production in dairy cows?
}

\author{
L. Zetouni, ${ }^{1}$ G. F. Difford, ${ }^{\star} \dagger$ J. Lassen,† M. V. Byskov,§ E. Norberg, ${ }^{*} \#$ and P. Løvendahl* \\ *Department of Molecular Biology and Genetics, Center For Quantitative Genetics and Genomics, Aarhus University, Blichers Alle, 8830, Tjele, \\ Denmark \\ †Wageningen University \& Research Animal Breeding and Genomics, $6700 \mathrm{AH}$, Wageningen, the Netherlands \\ $\ddagger$ Viking Genetics, Ebeltoftvej 16, Assentoft, 8960 Randers, Denmark \\ $\S S E G E S$, Dairy \& Beef Research Center, 8200 Skejby, Denmark \\ \#Department of Animal and Aquacultural Sciences, Norwegian University of Life Sciences, 1430 Ås, Norway
}

\section{ABSTRACT}

As long as large-scale recording of expensive-to-measure and labor-consuming traits, such as dry matter intake (DMI) and $\mathrm{CH}_{4}$ production $\left(\mathrm{CH}_{4} \mathrm{P}\right)$, continues to be challenging in practical conditions, alternative traits that are already routinely recorded in dairy herds should be investigated. An ideal indicator trait must, in addition to expressing genetic variation, have a strong correlation with the trait of interest. Our aim was to estimate individual level and phenotypic correlations between rumination time (RT), $\mathrm{CH}_{4} \mathrm{P}$, and DMI to determine if $\mathrm{RT}$ could be used as an indicator trait for $\mathrm{CH}_{4} \mathrm{P}$ and DMI. Data from 343 Danish Holstein cows were collected at the Danish Cattle Research Centre for a period of approximately $3 \mathrm{yr}$. The data set consisted of 14,890 records for DMI, 15,835 for RT, and 6,693 for $\mathrm{CH}_{4} \mathrm{P}$. Data were divided in primiparous cows only (PC) and all cows (MC), and then divided in lactation stage (early, mid, late, and whole lactation) to analyze the changes over lactation. Linear mixed models, including an animal effect but no pedigree, were used to estimate the correlations among traits. Phenotypic and individual level correlations between RT and both $\mathrm{CH}_{4} \mathrm{P}$ and DMI were close to zero, regardless of lactation stage and data set ( $\mathrm{PC}$ or $\mathrm{MC}$ ). However, $\mathrm{CH}_{4} \mathrm{P}$ and DMI were highly correlated, both across lactation stages and data sets. In conclusion, RT is unsuitable to be used as an indicator trait for either $\mathrm{CH}_{4} \mathrm{P}$ or DMI. Our study failed to validate RT as a useful indicator trait for both $\mathrm{CH}_{4} \mathrm{P}$ and DMI, but more studies with novel phenotypes can offer different approaches to select and incorporate important yet difficult to record traits into breeding goals and selection indexes.

Key words: methane, rumination time, dry matter intake, dairy cow

Received December 13, 2017.

Accepted July 1, 2018.

${ }^{1}$ Corresponding author: lzetouni@mbg.au.dk

\section{INTRODUCTION}

Milk and milk products are of major importance for human nutrition. With the expected human population growth rate, reduction in milk production as an alternative to decreasing greenhouse gas emissions seems challenging. Nevertheless, greenhouse gas mitigation strategies for ruminant production systems have been extensively discussed with the anticipation of a carbon constrained economy (Wall et al., 2010; Knapp et al., 2014; Pickering et al., 2015). Ruminal $\mathrm{CH}_{4}$ production $\left(\mathbf{C H}_{4} \mathbf{P}\right)$ represents a loss of dietary energy for the animals (Johnson and Johnson, 1995); therefore, having strategies for reducing $\mathrm{CH}_{4}$ emissions from cows while maintaining or even increasing milk production levels seems to be the key for a sustainable development of the dairy industry worldwide (Pacheco et al., 2014).

Nutritional and microbial manipulations as attempts to reduce $\mathrm{CH}_{4}$ emissions have been and still are explored (Cottle et al., 2011), and the investigation of animal variation for $\mathrm{CH}_{4} \mathrm{P}$ has made some progress in the past few years (for a more broad perspective, see de Haas et al., 2017). However, breeding for lower emitting cows as a mitigation strategy has proven to be challenging, mainly due to the difficulty in obtaining $\mathrm{CH}_{4}$ records on a large number of related individuals, which is required for genetic evaluations. The gold standard for $\mathrm{CH}_{4}$ recording is the respiration chamber, but this is an expensive and labor-consuming method (Pickering et al., 2015). Confinement within the artificial environment of the chambers can affect cows' feeding behavior, resulting in a drop in DMI and $\mathrm{CH}_{4} \mathrm{P}$ (Storm et al., 2012); therefore, the validity of results under commercial conditions may be questioned (Lassen and Løvendahl, 2016).

As far as inexpensive, less time-consuming methods for $\mathrm{CH}_{4}$ records are concerned, some innovative techniques have been proposed (see Patra, 2016), such as the sniffer gas concentration methods (Garnsworthy et al., 2012; Lassen et al., 2012). This is a noninvasive technique that can be installed inside the integral feed 
bins of automatic milking systems (AMS) or concentrate feeders, where it continuously measures $\mathrm{CH}_{4}$ concentration during milking, and several hundred measurements can be made in a very short time (Lassen and Løvendahl, 2016). However, implementation of this technology would only be applicable with the use of AMS or concentrate feeders in commercial farms, and further calculations are required to obtain a $\mathrm{CH}_{4}$ mass flux estimate (Madsen et al., 2010; Garnsworthy et al., 2012).

Another alternative for exploring the genetic variation in the $\mathrm{CH}_{4}$ emitting potential of cows is the use of indicator traits related to $\mathrm{CH}_{4} \mathrm{P}$ (Negussie et al., 2017). To identify potential traits that could be closely related to $\mathrm{CH}_{4} \mathrm{P}$, it is important to consider the factors that are known to contribute to $\mathrm{CH}_{4}$ synthesis. Intake and diet composition have a major influence on the animal's emission potential (Jentsch et al., 2007); therefore, possible indicator traits for $\mathrm{CH}_{4} \mathrm{P}$ could be traits that are influenced by the same factors. For instance, feeding rations high in forage NDF stimulates rumination activity, and also aids the production of acetate production in the rumen, leading to higher $\mathrm{CH}_{4} \mathrm{P}$ (Mendes et al., 2013; Byskov et al., 2015).

Rumination time (RT) could be an appealing alternative because some of the factors that influence $\mathrm{CH}_{4} \mathrm{P}$ in cows can also affect RT. For instance, RT also increases with the inclusion of high levels of fiber in the animal's diet. Moreover, rumination increases saliva production, buffering rumen's $\mathrm{pH}$ (Mertens, 1997), favoring acetate production, leading to more enteric $\mathrm{CH}_{4}$ (Moe and Tyrrell, 1979). Rumination time could affect feed particle size through mastication, and thus microbial fermentation which also seems to have an effect on digesta turnover (Watt et al., 2015), which can have an effect on the regulations of DMI through homeorhetic controls of satiation (Allen, 2000), therefore potentially affecting $\mathrm{CH}_{4} \mathrm{P}$. Large-scale recording of RT is already possible in commercial herds with a noninvasive sensor-based system that measures rumination activity sounds produced by the cow's jaw or ear movements (Schirmann et al., 2009). Thus, the objective of this study was to investigate the possible phenotypic relationships between RT and $\mathrm{CH}_{4} \mathrm{P}$ in Danish Holstein cows, to evaluate the feasibility of using RT as an indicator for $\mathrm{CH}_{4} \mathrm{P}$.

\section{MATERIALS AND METHODS}

\section{Animals, Facilities, and Feeding}

Data were collected at the Danish Cattle Research Centre (DCRC, Foulum, Denmark). The cows were housed in a freestall barn and were milked in an AMS (DeLaval, Tumba, Sweden). The DCRC barn is described in detail by Bossen and Weisbjerg (2009) and Bossen et al. (2009). Data on feed intake (both TMR and concentrate) are recorded automatically at DCRC. As records were collected across different trials, the TMR varied in nutritional content. Cows had ad libitum access to TMR, and up to $3 \mathrm{~kg}$ of daily concentrate was offered to the cows inside the AMS to attract the animals to the AMS. Feed intake data used in this study were previously presented by Li et al. (2016).

\section{Data Recording}

Feed bins (Insentec, Marknesse, the Netherlands) were used to measure individual intake. The cows had access to the bins through gates controlled by radio frequency identification ear tags. Daily feed intake values were obtained by summing the amount of feed consumed in all the visits made per cow, per day. Daily DMI values were calculated based on the DM content of the feed offered to each cow, according to the trial the cow was involved in. Dry matter content of individual TMR was analyzed within each trial. Daily DMI used in this study was recorded from May 2013 to November 2016.

Rumination time data were obtained by a microphone-based monitoring sensor (RuminAct by SCR Engineers Ltd., Netanya, Israel) placed on the left side of the cows' necks. The sensor uses the sound of regurgitation of feed boluses to identify when the cow is ruminating, and it also considers the sound pattern behavior expressed by the animals during rumination. Measurements of RT were recorded by the sensor in 2-h intervals; therefore, daily RT per animal had a total of twelve 2-h intervals per day. Data for RT include the period from May 2013 to January 2017.

Gas concentrations $\left(\mathrm{CH}_{4}\right.$ and $\left.\mathrm{CO}_{2}\right)$ in the breath of individual cows were obtained during milking, with one infrared gas analyzer per AMS (Guardian NG/Gascard, Edinburgh Instruments Ltd., Livingston, UK). The installation, calibration, signal processing, and calculation of daily $\mathrm{CH}_{4}$ and $\mathrm{CO}_{2}$ concentration per cow using the sniffers sensors at DCRC are described elsewhere (Difford et al., 2016). Data for $\mathrm{CH}_{4}$ and $\mathrm{CO}_{2}$ include the period of June 2013 to November 2016.

\section{Data Editing}

For each phenotype, weekly averages were calculated (DMI, RT, and $\mathrm{CH}_{4} \mathrm{P}$ ), for each cow. Only cows up to the third parity were included in this study. The total data set consisted of 343 Holstein cows, from which 273 had first parity records, 87 cows had both first and second parities records, and 55 had records from first to third parities available. The 70 cows without 
first parity records were kept in the data set due to the limited number of records available, from which 12 had information on second parity only, 21 only had records from their third parity, and 37 cows had records from both second and third parities available. Only data from wk 1 to 44 after calving were considered in this study. In total, there were 14,890 DMI records (6,756 from primiparous animals), 15,835 RT records (7,121 from primiparous animals), and $6,693 \mathrm{CH}_{4} \mathrm{P}$ records (3,152 from primiparous animals).

For DMI, only records within a range of 5 to $42 \mathrm{~kg} / \mathrm{d}$ were considered, and a maximum of 2 missing records per weekly average was allowed; therefore, records of cows with more than 2 missing records per week were excluded. For RT, unrealistic values caused by either sensor errors or disturbed rumination behavior due to heat were excluded from the analyses. Days that had missing 2-h intervals records were excluded; however, for the weekly averages incomplete weeks, meaning weeks without records every day, were considered due to the limited number of records available. Daily $\mathrm{CH}_{4}$ and $\mathrm{CO}_{2}$ concentration were screened for outliers due to instrument blockages by removing values exceeding 5 standard deviations from the mean. Weekly averages for $\mathrm{CH}_{4}$ and $\mathrm{CO}_{2}$ concentration were computed with a maximum missing value of 2 records per week. Weekly averages of $\mathrm{CO}_{2}$ production were calculated using a prediction equation for heat production units, based on ECM, BW, and days in pregnancy for each individual cow, and further converted from heat production units to $\mathrm{CO}_{2}$ L/d (CIGR, 2002; Pedersen et al., 2008). The measured $\mathrm{CH}_{4}$ and $\mathrm{CO}_{2}$ concentrations were used to compute the ratio of the 2 gases in the breath of cows and multiplied by the predicted $\mathrm{CO}_{2}$ production as a tracer gas to obtain methane production in $\mathrm{L} / \mathrm{d}\left(\mathrm{CH}_{4} \mathrm{P}\right.$; Madsen et al., 2010).

\section{Data Analysis}

Two main data sets were used in this study: one with primiparous (PC) cows only, and a data set containing records from first, second, and third parity cows (MC). Lactation weeks were divided into 11 periods, each period representing 4 lactation weeks. Period 1 would cover lactation wk 1 to 4 , period 2 for lactation wk 5 to 8 , and so on. To explore the potential variation across the different stages of lactation, parameters estimation was done first on whole lactation records (periods 1-11, wk 1-44), and posteriorly by splitting each data set in 3 subsets: early (periods 1-2, wk 1-8), mid (periods 5-6, wk 17-24), and late (periods 10-11, wk 37-44) lactation. Statistical differences between means among lactation stages for each data set (PC and MC) were estimated by using the PROC MIXED procedure in SAS (version 9.4, SAS Institute Inc., Cary, NC).

A repeatability model with the animal effect included but without pedigree-derived relationship matrices was used to estimate the individual level and phenotypic correlations between the traits. For the PC data set, pairwise bivariate models with the following description were used within lactation stages (early, mid, and late),

$$
y_{i j k l}=\mu+Y S_{j}+C_{k}+a_{i}+e_{i j k l},
$$

where $y$ represents the dependent phenotype (DMI, in $\mathrm{kg} / \mathrm{d}$; RT, in $\min / \mathrm{d} ; \mathrm{CH}_{4} \mathrm{P}$, in $\left.\mathrm{L} / \mathrm{d}\right) ; \mu$ is the overall intercept; $Y S$ is the year-season effect $(j=17$ levels); $C$ is the effect of contemporary group (each group has its own AMS); $a_{i}$ is the random effect of cow $i$ with $\sim N D\left(\mathbf{0}, \mathbf{I} \sigma_{\text {cow }}^{2}\right)$, where $\mathbf{I}$ is an identity matrix and $\sigma_{\text {cow }}^{2}$ is the variance component of the animal effects, which accounts for the repeated records for individual cows; and $e$ corresponds to the random residual effect, with $\sim \operatorname{IND}\left(\mathbf{0}, \mathbf{I} \sigma_{e}^{2}\right)$, where $\sigma_{e}^{2}$ is the residual variance. For DMI and RT, the bivariate model used was the same as the one described above, but without the effect of $C$ as this was not significant for these traits. Model 1 was used for the entire first lactation (PC data set) with the inclusion of an added fixed effect of period (11 levels) to account for differences in stages of lactation.

For the MC data set, pairwise bivariate models with the following description were used within lactation stages (early, mid, and late) were

$$
y_{i j k l m}=\mu+P_{j}+Y S_{k}+C_{l}+a_{i}+e_{i j k l m},
$$

where $y$ represents the dependent phenotype (DMI, $\mathrm{RT}$, or $\left.\mathrm{CH}_{4} \mathrm{P}\right), \mu$ is the overall intercept; $P$ is the effect of lactation number ( $j=3$ levels), and the other elements are the same as previously explained for model 1. The effect of $C$ was not considered in the analysis for DMI and RT. Model 2 above was used for the entire MC data set with the added fixed effect of period (11 levels) to account for differences in stages of lactation.

Estimation of variance and covariance components was performed by DMU (Madsen and Jensen, 2014), using the average information residual maximum likelihood (AI)REML. Repeatability estimates $(t)$ were obtained from the variance components by using the equation

$$
t=\frac{\sigma_{a}^{2}}{\left(\sigma_{a}^{2}+\sigma_{e}^{2}\right)},
$$


Table 1. Number of records $(\mathrm{N})$, means, and SD for the weekly averages of the traits recorded for the whole lactation (wk 0-44) for data sets of primiparous cows (PC) and all cows (MC)

\begin{tabular}{lcccrc}
\hline & \multicolumn{2}{c}{$\mathrm{PC}$} & & \multicolumn{2}{c}{ MC } \\
\cline { 2 - 3 } \cline { 5 - 6 } Trait $^{1}$ & $\mathrm{~N}$ & Mean (SD) & & $\mathrm{N}$ & Mean (SD) \\
\hline DMI (kg/d) & 6,756 & $19.4(3.1)$ & & 14,890 & $22.0(4.0)$ \\
$\mathrm{RT} \mathrm{(min/d)}$ & 7,121 & $415.1(116.7)$ & & 15,835 & $443.2(112.9)$ \\
$\mathrm{CH}_{4} \mathrm{P}(\mathrm{L} / \mathrm{d})$ & 3,152 & $405.2(115.8)$ & & 6,693 & $446.9(131.0)$ \\
\hline
\end{tabular}

${ }^{1} \mathrm{RT}=$ rumination time; $\mathrm{CH}_{4} \mathrm{P}=\mathrm{CH}_{4}$ production

where $\sigma_{a}^{2}$ represents the variance between cow defined by $\sigma_{a}^{2}=\sigma_{a}^{2}+\sigma_{e}^{2}$, and $\sigma_{e}^{2}$ represents the residual error variance. Individual level correlations $(r t)$, were computed as the correlation between random cow effects using variance components as shown:

$$
r t=\frac{\sigma_{a 1, a 2}}{\sqrt{\sigma_{a 1}^{2}} \cdot \sqrt{\sigma_{a 2}^{2}}},
$$

where $\sigma_{a 1}$ and $\sigma_{a 2}$ are the random animal effects for different measures taken on the same animal. Standard errors of covariance components were used to calculate the standard errors for the correlations estimated by using a Taylor series expansion (Madsen and Jensen, 2014).

\section{RESULTS}

\section{Descriptive Statistics}

Descriptive results for both data sets (PC and MC) across the whole lactation can be seen in Table 1. Table 2 contains the summary statistics for both PC and MC data sets, divided in early, mid, and late lactation stag- es, and Figures 1 and 2 present the trajectory profiles calculated as simple means with the respective standard errors between traits over lactation. Dry matter intake was the lowest during early lactation, being statistically different from DMI during mid and late lactation for both PC and MC. The same pattern was found for $\mathrm{CH}_{4} \mathrm{P}$, with the lowest production levels in early lactation, increasing significantly in mid lactation. However, $\mathrm{CH}_{4} \mathrm{P}$ decreased during late lactation, but this drop was not statistically different from the mid lactation stage. Interestingly, RT was highest during late lactation, whereas the values were not significantly different between early and mid lactation in PC cows (Figure 1). For MC cows a trend in RT was clearer, with the lowest values in mid lactation and the highest in early and late lactation. However, the differences in RT over lactation stages were not significant (Table 2). Visual inspection of the residual plots from the linear mixed models showed phenotypes are normally distributed.

\section{Individual Level and Phenotypic Correlations}

Individual and phenotypic correlations among traits were estimated separately for each data set (PC and $\mathrm{MC}$ ), for each lactation stage considered (early, mid,

Table 2. Number of records (N), means, and SD for the traits recorded, divided into early, mid, and late lactation stages, for primiparous cows $(\mathrm{PC})$ and all cows $(\mathrm{MC})$

\begin{tabular}{|c|c|c|c|c|c|c|c|}
\hline \multirow[b]{2}{*}{ Data set } & \multirow[b]{2}{*}{ Trait $^{1}$} & \multicolumn{6}{|c|}{ Lactation stage ${ }^{2}$} \\
\hline & & $\mathrm{N}$ & Mean (SD) & $\mathrm{N}$ & Mean (SD) & $\mathrm{N}$ & Mean (SD) \\
\hline \multicolumn{8}{|l|}{$\overline{\mathrm{PC}}$} \\
\hline & DMI (kg/d) & 1,548 & $15.7^{\mathrm{a}}(5.9)$ & 1,226 & $19.9^{\mathrm{b}}(5.5)$ & 832 & $20.0^{\mathrm{b}}(5.0)$ \\
\hline & $\mathrm{RT}(\mathrm{min} / \mathrm{d})$ & 1,530 & $403.2^{\mathrm{a}}(267.9)$ & 1,259 & $403.1^{\mathrm{a}}(245.3)$ & 1,154 & $430.5^{\mathrm{b}}(244.2)$ \\
\hline \multirow{2}{*}{$\mathrm{MC}$} & $\mathrm{RT}(\mathrm{min} / \mathrm{d})$ & 3,403 & $446.2^{\mathrm{a}}(310.3)$ & 2,879 & $441.4^{\mathrm{ab}}(293.8)$ & 2,455 & $451.2^{\mathrm{a}}(285.7)$ \\
\hline & $\mathrm{CH}_{4} \mathrm{P}(\mathrm{L} / \mathrm{d})$ & 1,515 & $421.0^{\mathrm{a}}(181.0)$ & 1,220 & $461.2^{\mathrm{b}}(174.6)$ & 872 & $440.0^{\mathrm{c}}(162.6)$ \\
\hline
\end{tabular}

${ }^{\mathrm{a}-\mathrm{c}}$ Different letters in the same row indicate statistically different means $(P<0.001)$.

${ }^{1} \mathrm{RT}=$ rumination time; $\mathrm{CH}_{4} \mathrm{P}=\mathrm{CH}_{4}$ production.

${ }^{2}$ Early $=$ lactation wk 1-8; mid = lactation wk 27-34; late = lactation wk 37-44. 
and late) and for the whole lactation period (Tables 3 and 4). The individual level and phenotypic correlations between RT and the other traits were weak and close to zero, ranging from $(-0.11$ to 0.11$)$ in the $\mathrm{PC}$ data set, regardless of lactation stage (whole, early, mid, and late). The range of correlations further decreased to ( -0.08 to 0.02$)$ with the addition of more records from the MC data. However, the individual level and phenotypic correlations between $\mathrm{CH}_{4} \mathrm{P}$ and DMI were strong and positive, ranging from $(0.64-0.75)$ for individual level correlations over lactation in the PC data set and (0.57-0.71) for phenotypic correlations. The strong individual level correlations between $\mathrm{CH}_{4} \mathrm{P}$ and DMI were also observed in the MC data set, regardless of the cows' age and their physiological and lactation stages. Individual level correlations ranged from 0.63 to 0.76 , and from 0.57 to 0.72 for phenotypic correlations.

Figures 3, 4, and 5 show pairwise relationships of the random cow solutions from the model described in [1] and support the weak individual level correlations between RT and the other traits showing no visible linear associations with $\mathrm{CH}_{4} \mathrm{P}$ and DMI (Figures 3 and 4). The strong individual level correlations between $\mathrm{CH}_{4} \mathrm{P}$ and DMI exhibited a clear linear relationship. For the
MC random cow solutions from model (2) the pairwise plots were largely the same as those in Figures 3, 4, and 5 (results not shown).

\section{DISCUSSION}

Daily averages for DMI, RT, and $\mathrm{CH}_{4} \mathrm{P}$ were lower in the PC data set, which was expected because the smaller body of primiparous cows have an effect on their intake. Consequently, we would expect average $\mathrm{CH}_{4} \mathrm{P}$ to be lower for primiparous cows as well, due to the strong positive correlation between DMI and $\mathrm{CH}_{4} \mathrm{P}$ (Yan et al., 2000; Hristov et al., 2013). Also, Soriani et al. (2012) have shown that changes in the environment during the transition period affect primiparous cows more than multiparous cows, leading them to ruminate less. Regarding the correlations between traits estimated in our study, an alternative approach of estimating individual level and phenotypic correlations was used. It is challenging to obtain meaningful genetic correlations between possible indicator traits and expensive or difficult to measure traits (such as $\mathrm{CH}_{4}$ or DMI), as the number of records is usually too limited to estimate genetic correlations reliably. Individual level correlations

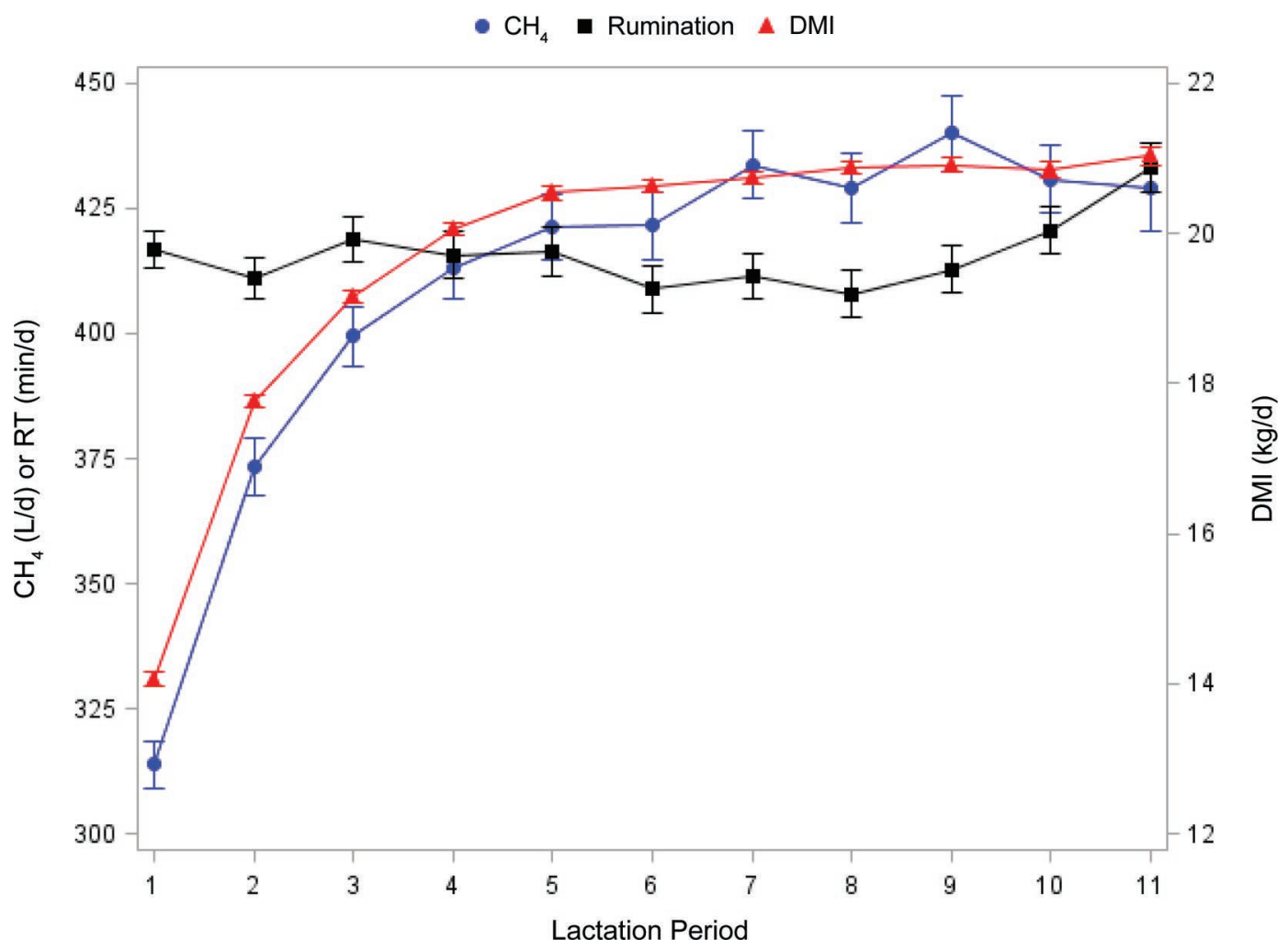

Figure 1. Dry matter intake, $\mathrm{CH}_{4}$ production $\left(\mathrm{CH}_{4}\right)$, and rumination time $(\mathrm{RT})$ in primiparous lactating Holstein cows across lactation periods (1-11); error bars denote SE. Color version available online. 
Table 3. Phenotypic (above diagonal) and individual level correlations (below diagonal) among traits and repeatability (diagonal) of traits followed by SE, for primiparous cows only estimated over the whole lactation, and during early, mid, and late lactation stages

\begin{tabular}{|c|c|c|c|c|}
\hline Lactation stage & Trait $^{1}$ & DMI & $\mathrm{RT}$ & $\mathrm{CH}_{4} \mathrm{P}$ \\
\hline \multicolumn{5}{|l|}{ Whole } \\
\hline & DMI & $0.60(0.02)$ & $-0.05(0.06)$ & $0.62(0.05)$ \\
\hline & RT & $-0.07(0.06)$ & $0.77(0.01)$ & $-0.08(0.06)$ \\
\hline & $\mathrm{CH}_{4} \mathrm{P}$ & $0.75(0.03)$ & $-0.10(0.07)$ & $0.74(0.02)$ \\
\hline \multicolumn{4}{|l|}{ Early } & $071 \quad(004)$ \\
\hline & $\mathrm{RT}$ & $0.01(0.08)$ & $0.83(0.01)$ & $0.06(0.06)$ \\
\hline & $\mathrm{CH}_{4} \mathrm{P}$ & $0.72(0.05)$ & $0.11(0.08)$ & $0.57(0.03)$ \\
\hline Mid & DMI & $0.72(0.02)$ & $-0.04(0.06)$ & $0.57(0.06)$ \\
\hline & RT & $-0.05(0.08)$ & $0.93(0.007)$ & $-0.11(0.06)$ \\
\hline & $\mathrm{CH}_{4} \mathrm{P}$ & $0.67(0.05)$ & $-0.13(0.09)$ & $0.77(0.03)$ \\
\hline \multicolumn{5}{|l|}{ Late } \\
\hline & DMI & $0.75(0.03)$ & $-0.04(0.06)$ & $0.57(0.06)$ \\
\hline & RT & $-0.04(0.08)$ & $0.84(0.02)$ & $-0.09(0.06)$ \\
\hline & $\mathrm{CH}_{4} \mathrm{P}$ & $0.64(0.06)$ & $-0.11(0.10)$ & $0.73(0.03)$ \\
\hline
\end{tabular}

${ }^{1} \mathrm{RT}=$ rumination time; $\mathrm{CH}_{4} \mathrm{P}=\mathrm{CH}_{4}$ production.

(sometimes called repeated measures correlation) are viable when repeated measures are made per subject and the measurement is prone to error (i.e., $\mathrm{t} \leq 0.80$ ), but the number of individuals is too low to estimate genetic correlations reliably (Løvendahl et al., 2010; Bakdash and Marusich, 2017). Although the standard errors of both correlations are similar in magnitude, the phenotypic correlations are prone to downward bias,

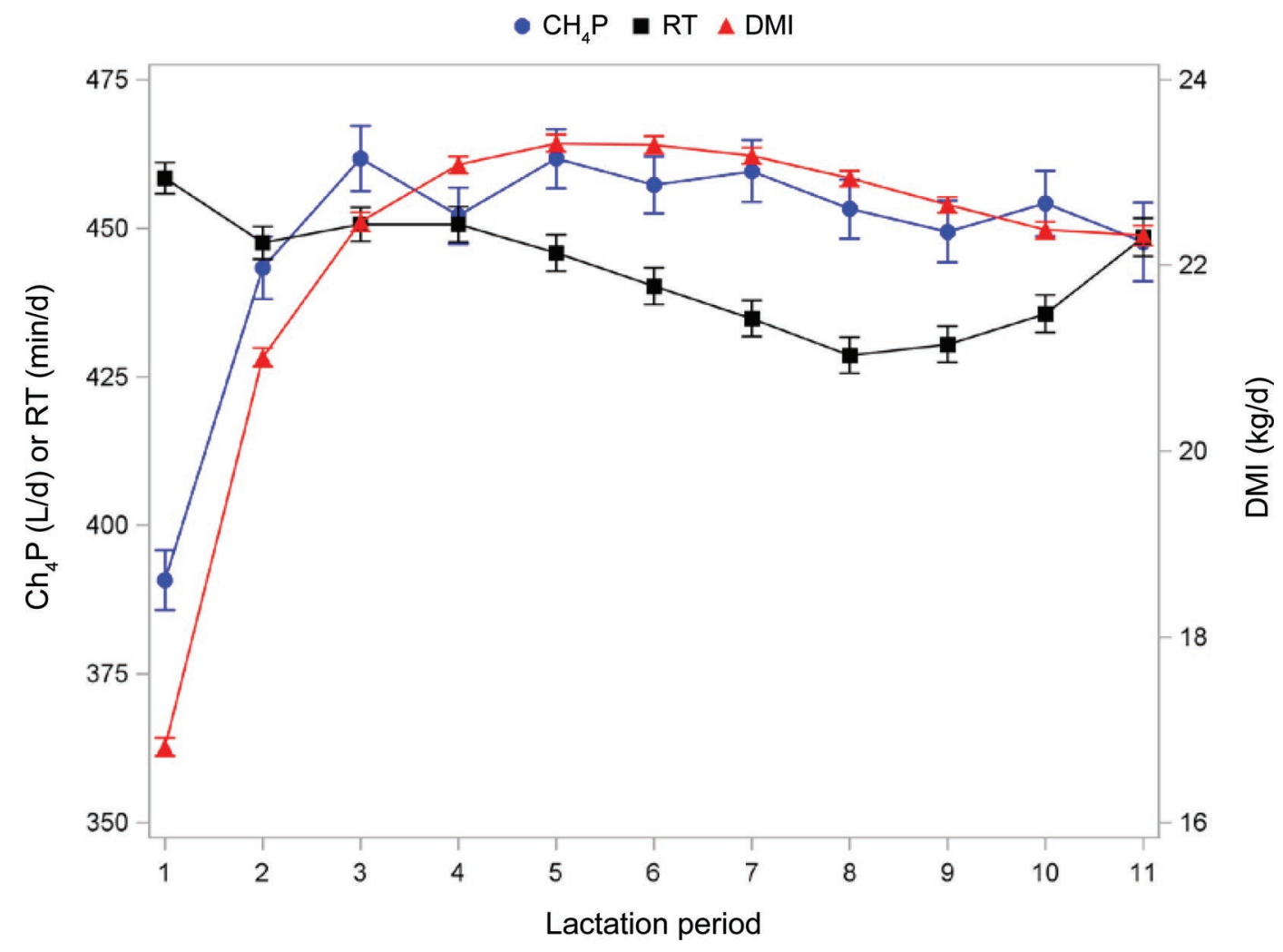

Figure 2. Dry matter intake, $\mathrm{CH}_{4}$ production $\left(\mathrm{CH}_{4} \mathrm{P}\right)$, and rumination time (RT) in multiparous lactating Holstein cows across lactation periods (1-11); error bars denote SE. Color version available online. 
Table 4. Phenotypic (above diagonal) and individual level correlations (below diagonal) among traits and repeatability (diagonal) of traits followed by SE, for the full data set estimated over the whole lactation, and during early, mid, and late lactation stages

\begin{tabular}{|c|c|c|c|c|}
\hline Lactation stage & Trait $^{1}$ & DMI & $\mathrm{RT}$ & $\mathrm{CH}_{4} \mathrm{P}$ \\
\hline \multicolumn{5}{|l|}{ Whole } \\
\hline & DMI & $0.54(0.02)$ & $-0.02(0.05)$ & $0.63(0.04)$ \\
\hline & $\mathrm{RT}$ & $-0.04(0.06)$ & $0.70(0.02)$ & $-0.05(0.05)$ \\
\hline & $\mathrm{CH}_{4} \mathrm{P}$ & $0.76(0.03)$ & $-0.08(0.06)$ & $0.67(0.02)$ \\
\hline \multicolumn{5}{|l|}{ Early } \\
\hline & DMI & $0.28(0.03)$ & $-0.07(0.05)$ & $0.65(0.04)$ \\
\hline & $\mathrm{RT}$ & $-0.02(0.07)$ & $0.73(0.02)$ & $-0.003(0.06)$ \\
\hline & $\mathrm{CH}_{4} \mathrm{P}$ & $0.69(0.04)$ & $0.02(0.07)$ & $0.54(0.02)$ \\
\hline vinu & DMI & $0.63(0.02)$ & $-0.03(0.06)$ & $0.52(0.05)$ \\
\hline & RT & $-0.06(0.07)$ & $0.79(0.02)$ & $-0.09(0.06)$ \\
\hline & $\mathrm{CH}_{4} \mathrm{P}$ & $0.63(0.05)$ & $-0.09(0.07)$ & $0.71(0.02)$ \\
\hline \multicolumn{5}{|l|}{ Late } \\
\hline & RT & $0.03(0.07)$ & $0.73(0.02)$ & $-0.09(0.06)$ \\
\hline & $\mathrm{CH}_{4} \mathrm{P}$ & $0.71(0.04)$ & $-0.09(0.08)$ & $0.62(0.03)$ \\
\hline
\end{tabular}

${ }^{1} \mathrm{RT}=$ rumination time; $\mathrm{CH}_{4} \mathrm{P}=\mathrm{CH}_{4}$ production.

and as a result individual level correlations are closer to genetic correlations (Adolph and Hardin, 2007; Wolak et al., 2012).

\section{$\mathrm{RT}$ as an Indicator Trait for $\mathrm{CH}_{4}$ Production}

To our knowledge, individual level and phenotypic correlations between $\mathrm{RT}$ and $\mathrm{CH}_{4} \mathrm{P}$ in lactating dairy cows were not discussed in any other studies. A relationship would be expected because $\mathrm{RT}$ and $\mathrm{CH}_{4} \mathrm{P}$ are both influenced by fiber intake, rate of passage of digesta, and rumen fermentation (Moe and Tyrrell, 1979; Mertens, 1997; Mendes et al., 2013). However, these factors can be seen to affect the relationships between $\mathrm{RT}$ and $\mathrm{CH}_{4} \mathrm{P}$ within cow due to nongenetic factors such as forage type, but do not necessarily hold between cows, which is the primary interest in genetic evaluations.

However, the findings from small-scale, short-term, and divergent studies have been inconsistent in defining the relationship between $\mathrm{CH}_{4} \mathrm{P}$ and RT. For instance, Pinares-Patiño et al. (2007) estimated a phenotypic correlation of -0.71 between $\mathrm{CH}_{4} \mathrm{P}$ and RT per $\mathrm{kg}$ of NDF (visually scored) in 9 nonlactating Holstein $\times$ Jersey cows and a correlation of -0.76 between RT in the first $3 \mathrm{~h}$ after feeding and $\mathrm{CH}_{4} \mathrm{P}$; however, back calculation from their significance tests reveals the SE to be $\sim 0.30$, demonstrating the limited value of the estimates. Watt et al. (2015) compared RT, $\mathrm{CH}_{4} \mathrm{P}$, and estimated DMI, between 2 groups $(\mathrm{n}=37)$ of lactating Holstein-Friesian cows selected for differential RT and found significant differences between groups for estimated DMI and $\mathrm{CH}_{4} \mathrm{P}$, indicating a correlation between RT, DMI, and $\mathrm{CH}_{4} \mathrm{P}$. However, the repeatabil- ity of RT was low $(\mathrm{t}=0.26)$ and significant group by test day interaction was detected; thus, the persistence of ranking of cows with high and low RT groups was poor. Chagunda et al. (2009) used a handheld laser and found that the $\mathrm{CH}_{4}$ concentration in the breath of ruminating Holstein-Friesland cows was significantly higher than when cows were feeding or idle, suggesting that cows which ruminate more will also produce more $\mathrm{CH}_{4}$. These studies differ from the present study because individual level correlations, which are free of the effects of lactation stage, diet, or parity, were not estimated.

The individual level and phenotypic correlations between $\mathrm{CH}_{4} \mathrm{P}$ and $\mathrm{RT}$ were weak and close to zero regardless of lactation stages and data set (PC or MC). However, a pattern was observed regarding the direction of the correlations: with the exception of the early lactation stage, phenotypic correlations between $\mathrm{CH}_{4} \mathrm{P}$ and RT were negative favorable. Even when considering more records from cows at different parities, there is no strong indication that between animal variation in $\mathrm{CH}_{4} \mathrm{P}$ is related to between animal variation in $\mathrm{RT}$.

\section{$R T$ as an Indicator Trait for DMI}

A positive relationship between RT and DMI was expected given the assumption that higher intakes would require a longer time spent ruminating (Schirmann et al., 2012). Simply examining the increasing means of both RT and DMI from primiparous cows to all parities cows in the present study would also support this notion. Furthermore, Krause et al. (2002) found a positive relationship between long-particle DMI and RT and Byskov et al. (2015) found that $32 \%$ of the variation in 


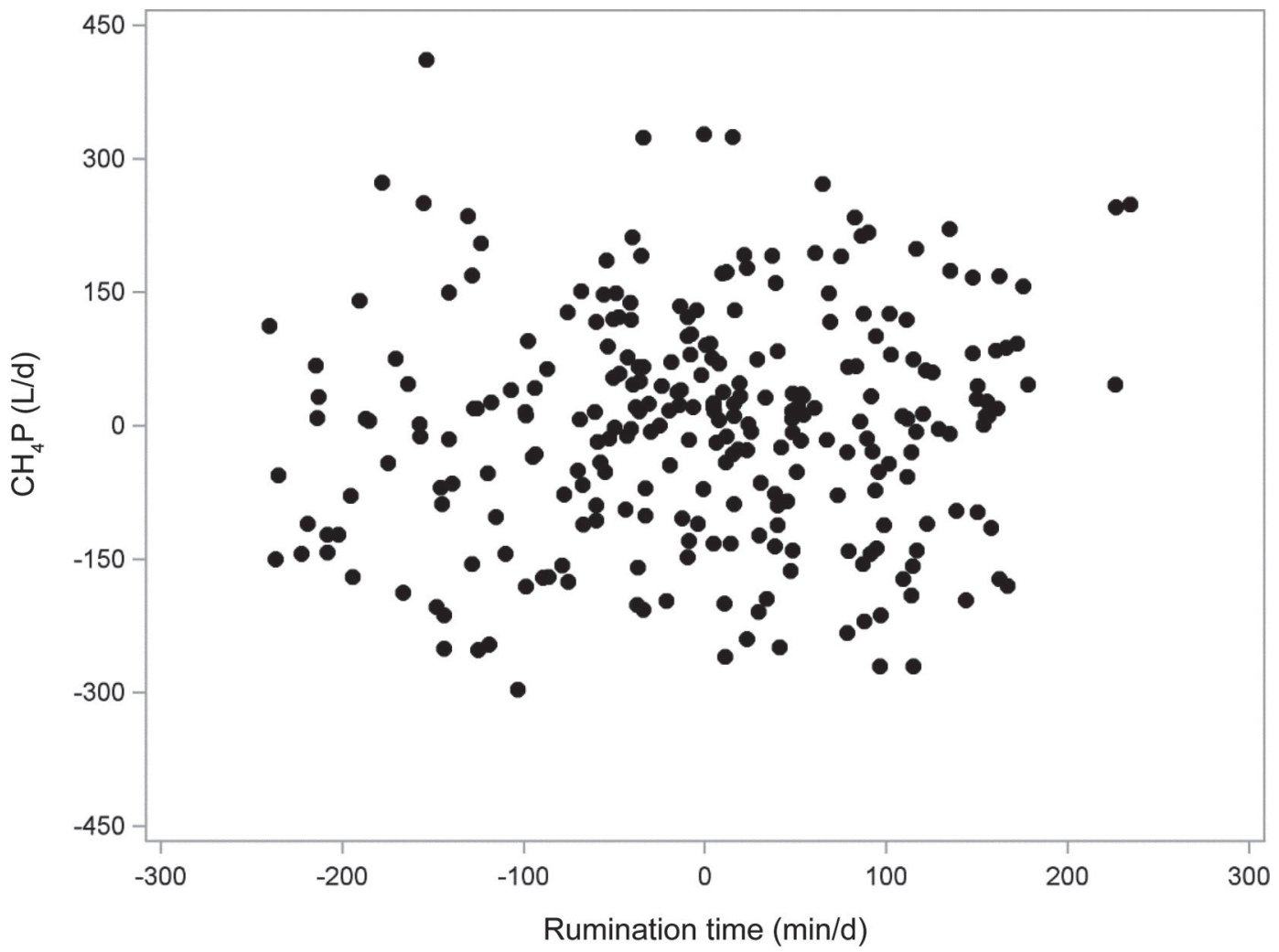

Figure 3. Individual level correlation between random cow solutions for $\mathrm{CH}_{4}$ production $\left(\mathrm{CH}_{4} \mathrm{P}\right)$ and rumination time of primiparous lactating Holstein cows.

RT was explained by dietary fractions. In our study, the individual level and phenotypic correlations estimated between RT and DMI were weak and close to zero, regardless of lactation stage or parity, indicating a poor relationship between the 2 traits. Similarly, Byskov et al. (2017) found phenotypic correlations between RT and DMI of -0.12 to 0.07 for whole and late lactation stages, and individual level correlations ranging from -0.24 to -0.09 in a similar data set, also concluding no clear relationship can be elaborated between both traits. Schirmann et al. (2012) found significant correlations positive correlations between daily DMI and RT within cow. However, the same conclusion was not reached by Schirmann et al. (2012) when comparing daily DMI and RT between cows, where no significant relationship between daily DMI and RT was detected. Our results corroborate with the previous findings that $\mathrm{RT}$ is not a suitable indicator for DMI in dairy cows.

\section{DMI as an Indicator Trait for $\mathrm{CH}_{4}$ Production}

A positive relationship was expected between DMI and $\mathrm{CH}_{4} \mathrm{P}$, as numerous authors have reported strong positive correlations $(>0.80)$ between these traits (Yan et al., 2000). Not surprisingly, prediction equations for
$\mathrm{CH}_{4} \mathrm{P}$ that exploit the relationship between these traits are ubiquitous in the scientific literature (Ellis et al., 2007; Hippenstiel et al., 2013). The individual level and phenotypic correlations estimated in this study confirm that $\mathrm{CH}_{4} \mathrm{P}$ and DMI are intrinsically connected in ruminants. de Haas et al. (2011) estimated the genetic and phenotypic correlations between $\mathrm{CH}_{4} \mathrm{P}$ (predicted from DMI) and DMI as close to unity and 0.72, respectively, in Dutch Holstein-Friesian. This finding agrees with the present results, indicating that DMI and $\mathrm{CH}_{4} \mathrm{P}$ could serve as genetic indicators for each other. Although the present study and the study of de Haas et al. (2011) both make use of prediction equations to estimate $\mathrm{CH}_{4} \mathrm{P}$, which may influence the estimated correlations between DMI and $\mathrm{CH}_{4} \mathrm{P}$, the phenotypic correlations are similar to those estimated using respiration chambers, supporting the validity of correlations in the present study (Yan et al., 2000).

It is important to note that $\mathrm{CH}_{4} \mathrm{P}$ is based on a prediction for $\mathrm{CO}_{2}$ production that ignores variation in ME utilization (Huhtanen et al., 2015). Improved efficiency at a fixed level of intake decreases $\mathrm{CO}_{2}$ production and thus increases the measured $\mathrm{CH}_{4} / \mathrm{CO}_{2}$ ratio. However, improved efficiency increases milk production and thus increases the predicted $\mathrm{CO}_{2}$ production using 


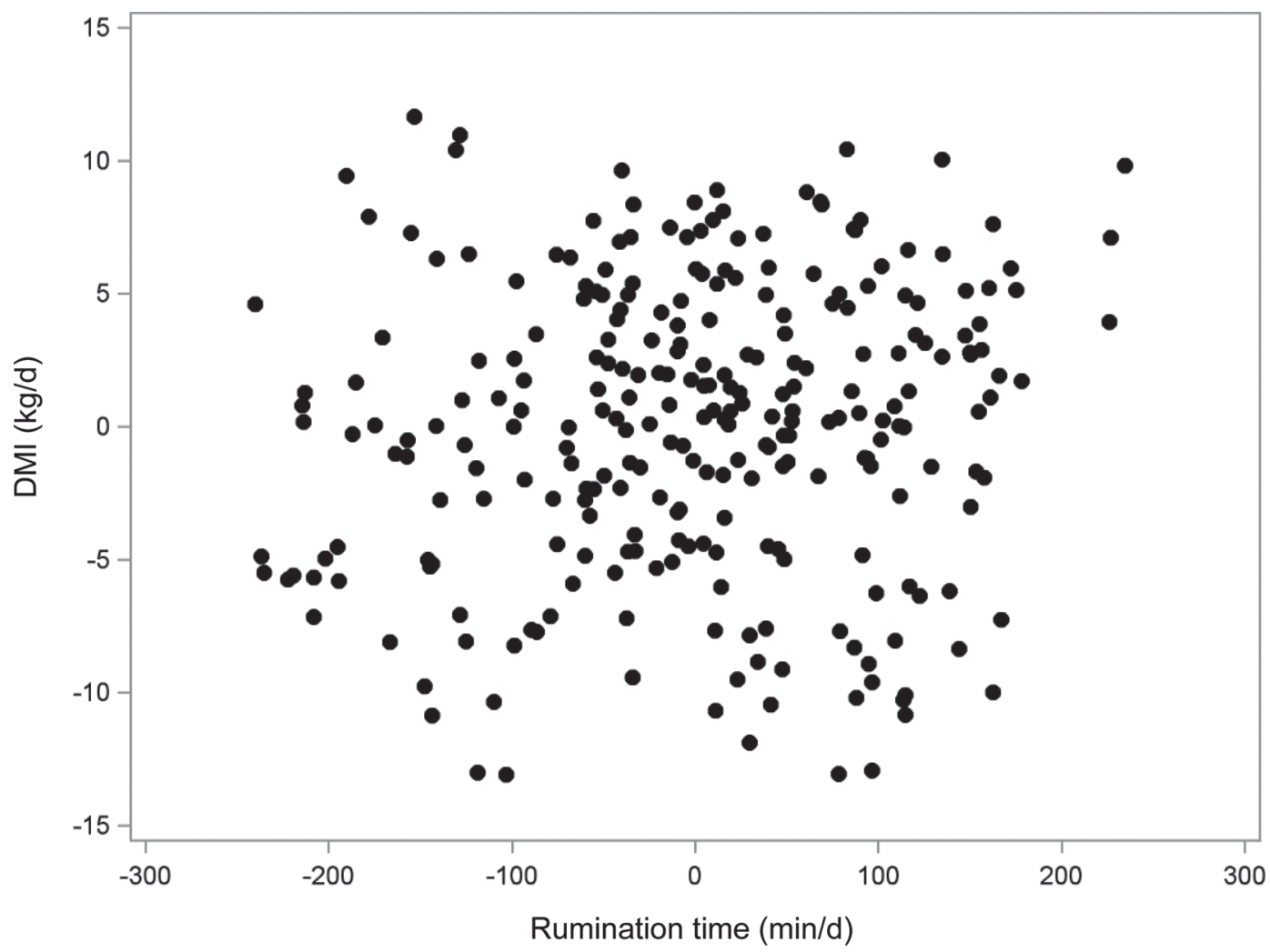

Figure 4. Individual level correlation between random cow solutions for DMI and rumination time of primiparous lactating Holstein cows.

the equation described in Madsen et al. (2010). As a result, $\mathrm{CH}_{4} \mathrm{P}$ could be overpredicted for efficient cows and underpredicted for inefficient cows. Furthermore, variation in BCS can cause large variation in predicted $\mathrm{CO}_{2}$ production using $\mathrm{BW}$ to estimate maintenance requirement (Huhtanen et al., 2015). Thus it would be expected that $\mathrm{CH}_{4} \mathrm{P}$ would be a poorer indicator of DMI during early lactation when variation in mobilization of body reserves and BCS would be expected to add variation to $\mathrm{CH}_{4} \mathrm{P}$ from the predicted $\mathrm{CO}_{2}$ production. However, in the present study in both the $\mathrm{PC}$ and the $\mathrm{MC}$ data sets the correlation between $\mathrm{CH}_{4} \mathrm{P}$ and DMI was higher during early lactation as opposed to mid and late lactation. Regardless, further research is required to full quantify the shortcomings of $\mathrm{CH}_{4} \mathrm{P}$ when predicted $\mathrm{CO}_{2}$ production is employed and variation in ME utilization is not taken into account.

\section{$R T$ as an Indicator Trait}

It is difficult to extrapolate about the correlations between RT, both within and between primiparous and multiparous cows, and other traits of interest. Despite being a highly repeatable and moderately heritable trait (Byskov et al., 2017) that is easily recordable in large-scale commercial herds, the results of this study and the study by Byskov et al. (2017) suggest that RT is unlikely to be a useful indicator trait for traits biologically related to rumination such as DMI, $\mathrm{CH}_{4} \mathrm{P}$, or feed efficiency. One of the factors that seem to be strongly correlated with RT is the cow's health status (Soriani et al., 2012). It also appears that changes in RT are related to the cow's response to acute stressors (Schirmann et al., 2011). Because RT is heritable and routinely recorded in a large number of cows, it would be of interest in future studies to determine if RT is a possible indicator trait for metabolic diseases.

\section{Implications}

Although the number of animals and records in the present study precluded direct estimations of genetic correlations between traits, the number of records and animals over lactation did provide reliable estimates of individual level and phenotypic correlations with low SE, implying that RT is unlikely to be a valuable indicator trait for $\mathrm{CH}_{4} \mathrm{P}$ or DMI. Furthermore, strong positive correlations were found between $\mathrm{CH}_{4} \mathrm{P}$ and DMI but the underlying link between these traits is unlikely to involve RT. Selection for lower $\mathrm{CH}_{4}$ emissions 


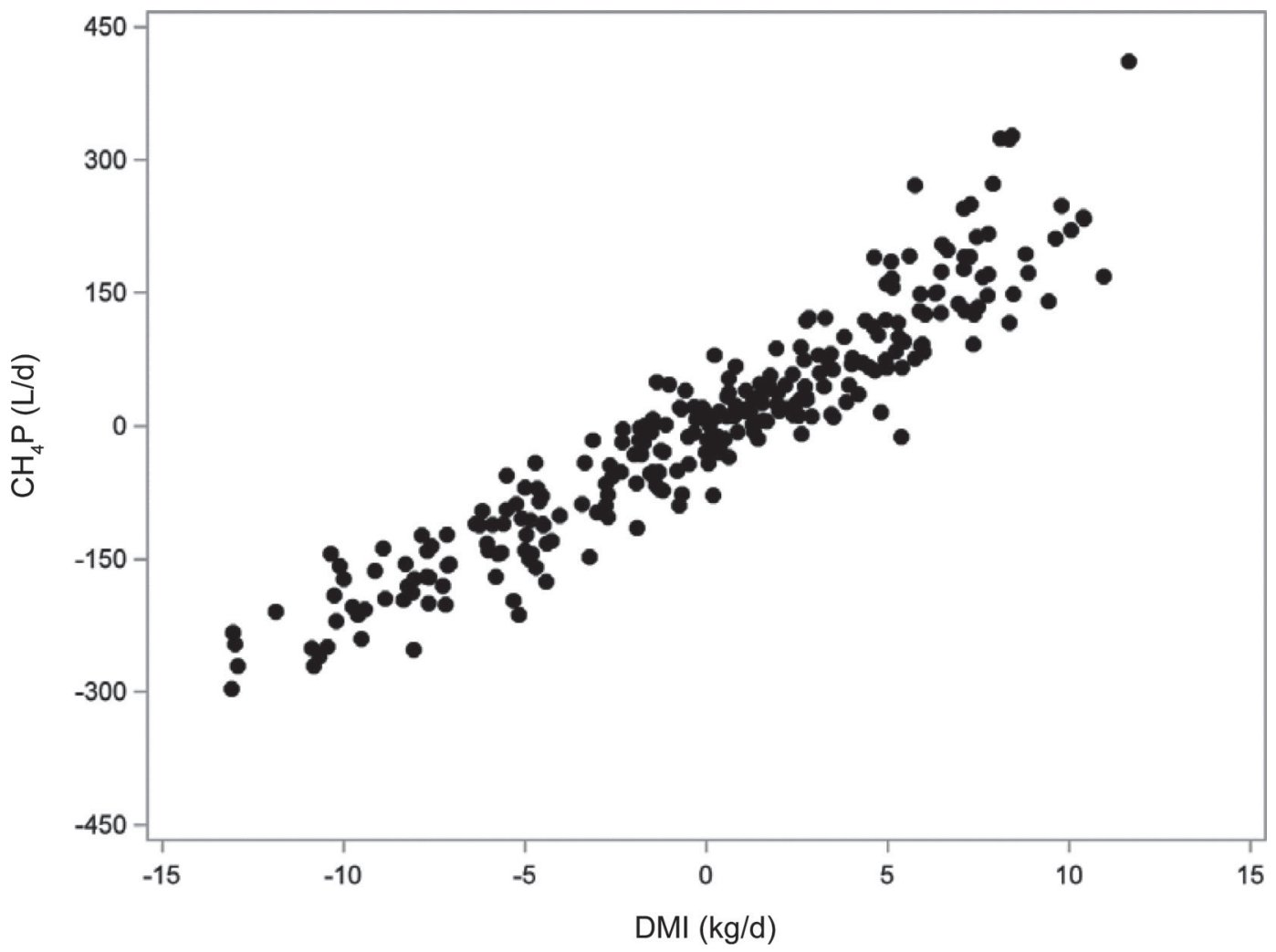

Figure 5. Individual level correlation between random cow solutions for $\mathrm{CH}_{4}$ production $\left(\mathrm{CH}_{4} \mathrm{P}\right)$ and DMI of primiparous lactating Holstein cows.

remains challenging and should not proceed without consideration of DMI.

\section{CONCLUSIONS}

The hypothesis that RT would serve as a valuable indicator trait of $\mathrm{CH}_{4} \mathrm{P}$ was not supported by our study. Individual level and phenotypic correlations between $\mathrm{RT}$ and $\mathrm{CH}_{4} \mathrm{P}$ were weak and close to zero, regardless of lactation stage and animal maturity. However, our study confirms the strong and already known phenotypic and individual level correlations between DMI and $\mathrm{CH}_{4} \mathrm{P}$. Given the relationships between $\mathrm{CH}_{4}$ and DMI, caution should be taken when considering implementation of $\mathrm{CH}_{4} \mathrm{P}$ in selection indexes without concomitant inclusion of DMI.

\section{ACKNOWLEDGMENTS}

This study was a part of the REFFICO project Robust and Efficient Dairy Cows, financed by Green Development and Demonstration Programme (GUDP; project number 34009-14-0848); REMRUM-Reduction of methane emissions from dairy cows and concurrent improvement of feed efficiency obtained through host genetics and next generation sequencing of rumen microbiome, funded by Strategic Research Council in Denmark (project number 12-132447); and Feed Utilization in Nordic Cattle (FUNC), which is a joint collaboration among Denmark, Finland, Norway, and Sweden. We are also very thankful to the staff at the Danish Cattle Research Center (Foulum, Denmark) for their commitment to caring for the animals and for providing us with the data. L. Zetouni was sponsored by the Brazilian scholarship program Science without Borders (National Council for Scientific and Technological Development-CNPq, Brasilia, Brazil), and would like to thank the EU COST-Action METHAGENE for financial support for a Short-Term Scientific Mission (STSM) related to this project.

\section{REFERENCES}

Adolph, S. C., and J. S. Hardin. 2007. Estimating phenotypic correlations: Correcting for bias due to intraindividual variability. Funct. Ecol. 21:178-184. https://doi.org/10.1111/j.1365-2435.2006.01209 .x.

Allen, M. S. 2000. Effects of diet on short-term regulation of feed intake by lactating dairy cattle. J. Dairy Sci. 83:1598-1624. https:// doi.org/10.3168/jds.S0022-0302(00)75030-2. 
Bakdash, J. Z., and L. R. Marusich. 2017. Repeated measures correlation. Front. Psychol. 8:456. https://doi.org/10.3389/fpsyg.2017 .00456 .

Bossen, D., and M. R. Weisbjerg. 2009. Allocation of feed based on individual dairy cow live weight changes. II: Effect on milk production. Livest. Sci. 126:273-285. https://doi.org/10.1016/j.livsci .2009.07.011

Bossen, D., M. R. Weisbjerg, L. Munksgaard, and S. Højsgaard. 2009. Allocation of feed based on individual dairy cow live weight changes. I: Feed intake and live weight changes during lactation. Livest. Sci. 126:252-272. https://doi.org/10.1016/j.livsci.2009.07.010.

Byskov, M. V., A. Fogh, and P. Løvendahl. 2017. Genetic parameters of rumination time and feed efficiency research and commercial conditions. J. Dairy Sci. 100:9635-9642. https://doi.org/10.3168/ jds.2016-12511.

Byskov, M. V., E. Nadeau, B. E. O. Johansson, and P. Nørgaard. 2015 Variations in automatically recorded rumination time as explained by variations in intake of dietary fractions and milk production, and between-cow variation. J. Dairy Sci. 98:3926-3937. https:// doi.org/10.3168/jds.2014-8012.

Chagunda, M. G. G., D. Ross, and D. J. Roberts. 2009. On the use of a laser methane detector in dairy cows. Comput. Electron. Agric. 68:157-160. https://doi.org/10.1016/j.compag.2009.05.008.

CIGR. 2002. CIGR International Commission of Agricultural Engineering, Section II 4th Report of Working Group Climatization of Animal Houses Heat and Moisture Production. S. Pedersen and K. Sällvik, ed. Research Centre Bygholm. DIAS, Horsens, Denmark.

Cottle, D. J., J. V. Nolan, and S. G. Wiedemann. 2011. Ruminant enteric methane mitigation: A review. Anim. Prod. Sci. 51:491-514. https://doi.org/10.1071/AN10163.

de Haas, Y., M. Pszczola, H. Soyeurt, E. Wall, and J. Lassen. 2017. Invited review: Phenotypes to genetically reduce greenhouse gas emissions in dairying. J. Dairy Sci. 100:855-870. https://doi.org/ 10.3168/jds.2016-11246.

de Haas, Y., J. J. Windig, M. P. L. Calus, J. Dijkstra, M. de Haan, A. Bannink, and R. F. Veerkamp. 2011. Genetic parameters for predicted methane production and potential for reducing enteric emissions through genomic selection. J. Dairy Sci. 94:6122-6134. https://doi.org/10.3168/jds.2011-4439.

Difford, G. F., J. Lassen, and P. Løvendahl. 2016. Interchangeability between methane measurements in dairy cows assessed by comparing precision and agreement of two non-invasive infrared methods. Comput. Electron. Agric. 124:220-226. https://doi.org/10.1016/j .compag.2016.04.010.

Ellis, J. L., E. Kebreab, N. E. Odongo, B. W. McBride, E. K. Okine, and J. France. 2007. Prediction of methane production from dairy and beef cattle. J. Dairy Sci. 90:3456-3466. https://doi.org/10 $.3168 /$ jds.2006-675.

Garnsworthy, P. C., J. Craigon, J. Hernandez-Medrano, and N. Saunders. 2012. On-farm methane measurements during milking correlate with total methane production by individual dairy cows. J. Dairy Sci. 95:3166-3180. https://doi.org/10.3168/jds.2011-4605.

Hippenstiel, F., M. Pries, W. Büscher, and K. H. Südekum. 2013. Comparative evaluation of equations predicting methane production of dairy cattle from feed characteristics. Arch. Anim. Nutr. 67:279-288. https://doi.org/10.1080/1745039X.2013.793047.

Hristov, A. N., J. Oh, J. L. Firkins, J. Dijkstra, E. Kebreab, G. Waghorn, H. P. S. Makkar, A. T. Adesogan, W. Yang, C. Lee, P. J. Gerber, B. Henderson, and J. M. Tricarico. 2013. SPECIAL TOPICS-Mitigation of methane and nitrous oxide emissions from animal operations: I. A review of enteric methane mitigation options. J. Anim. Sci. 91:5045-5069. https://doi.org/10.2527/jas $.2013-6583$

Huhtanen, P., E. Cabezas-Garcia, S. Utsumi, and S. Zimmerman. 2015. Comparison of methods to determine methane emissions from dairy cows in farm conditions. J. Dairy Sci. 98:3394-3409. https://doi.org/10.3168/jds.2014-9118.

Jentsch, W., M. Schweigel, F. Weissbach, H. Scholze, W. Pitroff, and M. Derno. 2007. Methane production in cattle calculated by the nutrient composition of the diet. Arch. Anim. Nutr. 61:10-19. https://doi.org/10.1080/17450390601106580.
Johnson, K. A., and D. E. Johnson. 1995. Methane emissions from cattle. J. Anim. Sci. 73:2483-2492. https://doi.org/10.2527/1995 $.7382483 \mathrm{x}$

Knapp, J. R., G. L. Laur, P. A. Vadas, W. P. Weiss, and J. M. Tricarico. 2014. Invited review: Enteric methane in dairy cattle production: Quantifying the opportunities and impact of reducing emissions. J. Dairy Sci. 97:3231-3261. https://doi.org/10.3168/jds .2013-7234.

Krause, K. M., D. K. Combs, and K. A. Beauchemin. 2002. Effects of forage particle size and grain fermentability in mid lactation cows. II. Ruminal pH and chewing activity. J. Dairy Sci. 85:1947-1957. https://doi.org/10.3168/jds.S0022-0302(02)74271-9.

Lassen, J., and P. Løvendahl. 2016. Heritability estimates for enteric methane emissions from Holstein cattle measured using noninvasive methods. J. Dairy Sci. 99:1959-1967. https://doi.org/10 $.3168 /$ jds.2015-10012.

Lassen, J., P. Løvendahl, and J. Madsen. 2012. Accuracy of noninvasive breath methane measurements using Fourier transform infrared methods on individual cows. J. Dairy Sci. 95:890-898. https:/ /doi.org/10.3168/jds.2011-4544.

Li, B., W. Fikse, J. Lassen, M. Lidauer, P. Løvendahl, P. Mäntysaari, and B. Berglund. 2016. Genetic parameters for dry matter intake in primiparous Holstein, Nordic Red, and Jersey cows in the first half of lactation. J. Dairy Sci. 99:7232-7239. https://doi.org/10 .3168/jds.2015-10669.

Løvendahl, P., C. Ridder, and N. C. Friggens. 2010. Limits to prediction of energy balance from milk composition measures at individual cow level. J. Dairy Sci. 93:1998-2006. https://doi.org/10 $.3168 /$ jds.2009-2739.

Madsen, J., B. S. Bjerg, T. Hvelplund, M. R. Weisbjerg, and P. Lund. 2010. Methane and carbon dioxide ratio in excreted air for quantification of the methane production from ruminants. Livest. Sci. 129:223-227. https://doi.org/10.1016/j.livsci.2010.01.001.

Madsen, P., and J. Jensen. 2014. A user's guide to DMU, version 6 , release 5.0. Cent. Quant. Genet. Genomics Dept. Mol. Biol. Genet. Univ. Aarhus Res. Cent. Foulum, Tjele, Denmark.

Mendes, A. M. de P., D. K. de A. Silva, M. de A. Ferreira, A. S. C. Veras, G. D. G. Ferreira, R. B. Vigoderis, H. G. S. Arcanjo, J. M. Silva, J. S. de Almeida, A. C. A. Fotius, and G. de A. Farias 2013. Ingestive behavior of pastured crossbred dairy cows offered different supplement types. Trop. Anim. Health Prod. 45:231-237. https://doi.org/10.1007/s11250-012-0195-0.

Mertens, D. R. 1997. Creating a system for meeting the fiber requirements of dairy cows. J. Dairy Sci. 80:1463-1481. https://doi.org/ 10.3168/jds.S0022-0302(97)76075-2.

Moe, P. W., and H. F. Tyrrell. 1979. Methane production in dairy cows. J. Dairy Sci. 62:1583-1586. https://doi.org/10.3168/jds .S0022-0302(79)83465-7.

Negussie, E., Y. de Haas, F. Dehareng, R. J. Dewhurst, J. Dijkstra, N. Gengler, D. P. Morgavi, H. Soyeurt, S. van Gastelen, T. Yan, and F. Biscarini. 2017. Invited review: Large-scale indirect measurements for enteric methane emissions in dairy cattle: A review of proxies and their potential for use in management and breeding decisions. J. Dairy Sci. 100:2433-2453. https://doi.org/10.3168/ jds.2016-12030.

Pacheco, D., G. Waghorn, and P. H. Janssen. 2014. Decreasing methane emissions from ruminants grazing forages: A fit with productive and financial realities? Anim. Prod. Sci. 54:1141-1154. https: //doi.org/10.1071/AN14437.

Patra, A. K. 2016. Recent advances in measurement and dietary mitigation of enteric methane emissions in ruminants. Front. Vet. Sci. 3:39. https://doi.org/10.3389/fvets.2016.00039.

Pedersen, S., V. Blanes-Vidal, H. Joergensen, A. Chwalibog, A. Haeussermann, M. J. W. Heetkamp, and A. J. A. Aarnink. 2008 Carbon dioxide production in animal houses: A literature review. Agric. Eng. Int. CIGR Ejournal X:1-19. https://doi.org/10.1017/ CBO9781107415324.004

Pickering, N. K., V. H. Oddy, J. Basarab, K. Cammack, B. Hayes, R. S. Hegarty, J. Lassen, J. C. McEwan, S. Miller, C. S. Pinares-Patiño, and Y. de Haas. 2015. Animal board invited review: Genetic pos- 
sibilities to reduce enteric methane emissions from ruminants. Animal 9:1431-1440. https://doi.org/10.1017/S1751731115000968.

Pinares-Patiño, C. S., G. C. Waghorn, A. Machmüller, B. Vlaming, G. Molano, A. Cavanagh, and H. Clark. 2007. Methane emissions and digestive physiology of non-lactating dairy cows fed pasture forage. Can. J. Anim. Sci. 87:601-613. https://doi.org/10.4141/cjas06023.

Schirmann, K., N. Chapinal, D. Weary, W. Heuwieser, and M. von Keyserlingk. 2011. Short-term effects of regrouping on behavior of prepartum dairy cows. J. Dairy Sci. 94:2312-2319. https://doi .org/10.3168/jds.2010-3639.

Schirmann, K., N. Chapinal, D. M. Weary, W. Heuwieser, and M. A. G. von Keyserlingk. 2012. Rumination and its relationship to feeding and lying behavior in Holstein dairy cows. J. Dairy Sci. 95:3212-3217. https://doi.org/10.3168/jds.2011-4741.

Schirmann, K., M. A. G. von Keyserlingk, D. M. Weary, D. M. Veira, and W. Heuwieser. 2009. Technical note: Validation of a system for monitoring rumination in dairy cows. J. Dairy Sci. 92:6052-6055. https://doi.org/10.3168/jds.2009-2361.

Soriani, N., E. Trevisi, and L. Calamari. 2012. Relationships between rumination time, metabolic conditions, and health status in dairy cows during the transition period. J. Anim. Sci. 90:4544-4554. https://doi.org/10.2527/jas.2012-5064
Storm, I. M. L. D., A. L. F. Hellwing, N. I. Nielsen, and J. Madsen. 2012. Methods for measuring and estimating methane emission from ruminants. Animals (Basel) 2:160-183. https://doi.org/10 $.3390 /$ ani2020160.

Wall, E., G. Simm, and D. Moran. 2010. Developing breeding schemes to assist mitigation of greenhouse gas emissions. Animal 4:366. https://doi.org/10.1017/S175173110999070X.

Watt, L. J., C. E. F. Clark, G. L. Krebs, C. E. Petzel, S. Nielsen, and S. A. Utsumi. 2015. Differential rumination, intake, and enteric methane production of dairy cows in a pasture-based automatic milking system. J. Dairy Sci. 98:7248-7263. https://doi.org/10 .3168/jds.2015-9463.

Wolak, M. E., D. J. Fairbairn, and Y. R. Paulsen. 2012. Guidelines for estimating repeatability. Methods Ecol. Evol. 3:129-137. https:// doi.org/10.1111/j.2041-210X.2011.00125.x.

Yan, T., R. E. Agnew, F. J. Gordon, and M. G. Porter. 2000. Prediction of methane energy output in dairy and beef cattle offered grass silage-based diets. Livest. Prod. Sci. 64:253-263. https://doi .org/10.1016/S0301-6226(99)00145-1. 